\title{
PROFIL PERILAKU PENGELOLAAN OBAT PADA LANSIA
}

\author{
Ubaida Assalwa, Galuh P. Ningrum, Terid M. Tindawati, Sa'adatuz Zahro, Rizqa R. Trisfalia, Agnes P. \\ Yuliani, Firman Syarifudin, Adinda L.N Najah, Adelia S. Devi, Feriska Irmatiara, Yuni Priyandani* \\ Fakultas Farmasi, Universitas Airlangga \\ Gedung Nanizar Zaman Joenoes Kampus C, J1. Ir. Soekarno, Surabaya 60115, Indonesia
}

E-mail: yuni-p@ff.unair.ac.id

\begin{abstract}
ABSTRAK
Lansia (lanjut usia) adalah seseorang yang telah mencapai usia 60 tahun keatas. Pada usia ini terjadi penurunan fungsi organ (fisiologis), penurunan pengetahuan (kognitif), dan penurunan psikologis yang dapat menyebabkan komplikasi penyakit sehingga menyebabkan lansia menerima obat dalam jumlah yang banyak dan dapat mengakibatkan permasalahan dalam mengkonsumsi obat. Tujuan dari penelitian ini adalah untuk mengetahui profil perilaku pengelolaan obat pada lansia. Lokasi pengambilan data dilakukan di kelurahan Pucang Sewu pada tanggal 11-15 September 2019. Pemilihan sampel dilakukan secara purposive sampling. Data diambil dengan menggunakan kuesioner yang dibagikan kepada lansia. Variable penelitian ini meliputi cara mendapatkan, menggunakan, menyimpan, dan membuang obat yang digunakan oleh lansia. Dari 108 responden, sebanyak 51,85\% menjawab lansia menebus obat untuk dirinya sendiri, sebanyak 12,96\% keluarga lansia membantu lansia untuk minum obat, sejumlah 21,30\% menyimpan obat untuk lansia disembarang tempat, dan 60,19\% obat langsung dibuang ke tempat sampah tanpa dihancurkan/dikeluarkan isinya terlebih dahulu.
\end{abstract}

Kata kunci: lansia, pengelolaan obat, DAGUSIBU

\begin{abstract}
Elderly are age of 60 and above. Majority of elderly people may experience the decreased in organ function and metabolism which lead to multi comorbidities. Elderly with complex comorbidities may require multidrug therapies which sometimes cause a problem in the use of medication. The study aimed to observe the behavior profiles of drug management in elderly population. The data were collected using a selfadministered questionnaire in elderly population the Pucang Sewu district on 11 to 15 September 2019. The variables collected in this study were how to get, use, store, and dispose the medication used by the elderly. About 108 respondents agreed to participate in the study. About 51.85\% of the elderly stated that they purchased medications for themselves, while $12.96 \%$ of them were helped by their caregivers. Only, $21.30 \%$ respondents kept their medications at anyplace and $60.19 \%$ of participants disposed their medications directly to trashbin without being shattered beforehand.
\end{abstract}

Keywords: elderly, medication management, medication use 


\section{PENDAHULUAN}

Berdasarkan data proyeksi penduduk Pusat Data dan Informasi Kementerian Kesehatan Republik Indonesia tahun 2017 terdapat 23,66 juta jiwa penduduk lansia atau sebesar $9,03 \%$ dari keseluruhan jumlah penduduk Indonesia. Pada tahun 2020, jumlah penduduk lansia diprediksikan akan mencapai 27,08 juta penduduk lansia, dan jumlah tersebut akan terus meningkat seiring dengan pertambahan waktu. Jumlah penduduk lansia di Jawa Timur pada tahun 2017 mencapai $12,25 \%$. Hal ini menjadikan Jawa Timur sebagai salah satu dari 3 provinsi teratas dengan persentase penduduk lansia tersebar di Indonesia.

Menurut Peraturan Pemerintah Republik Indonesia Nomor 43 Tahun 2004, lanjut usia adalah seseorang yang telah mencapai usia 60 tahun keatas. Pada usia ini terjadi penurunan kemampuan untuk beradaptasi dengan lingkungan luar. Fungsional tubuh juga mengalami penurunan mulai dari penurunan fungsi organ (fisiologis), penurunan pengetahuan (kognitif), dan penurunan psikologis. Penurunan fungsional tubuh ini menyebabkan komplikasi penyakit mulai dari penyakit akut hingga penyakit kronis seperti hipertensi, diabetes, cardiovascular disease, stroke dll. Komplikasi penyakit dapat menyebabkan pasien lansia menerima obat dalam jumlah yang banyak (lebih dari 5 jenis obat) dalam sekali terapi atau yang biasa disebut dengan polifarmasi. Hal tersebut berpotensi menimbulkan permasalahan dalam ketidakpatuhan konsumsi obat yang dapat menurunkan kualitas hidup lansia. Penurunan fisiologis, kognitif, dan psikologis juga dapat menyebabkan kesalahpahaman dalam penggunaan obat.

Sehubungan dengan adanya potensi masalah tersebut, untuk itu perlu dilakukan survei untuk mengetahui perilaku pengelolaan obat pada lansia untuk meningkatkan kepatuhan pasien lansia dan menjamin penggunaan obat dengan benar agar tujuan terapi dapat tercapai. Berdasarkan Permenkes RI No. 35 tahun 2014 mengenai pelayanan kefarmasian di rumah (Home Pharmacy Care) dimana apoteker sebagai pemberi layanan diharapkan juga dapat melakukan pelayanan kefarmasian yang bersifat kunjungan rumah, khususnya untuk kelompok lansia dan pasien dengan pengobatan penyakit kronis lainnya. Adapun pelayanan kefarmasian di rumah yang dapat dilakukan oleh apoteker meliputi penilaian/pencarian (assessment) masalah yang berhubungan dengan pengobatan, identifikasi kepatuhan pasien, pendampingan pengelolaan obat dan/atau alat kesehatan di rumah, konsultasi masalah obatatau kesehatan secara umum, dan monitoring pelaksanaan, efektifitas dan keamanan penggunaan obat berdasarkan catatan pengobatan pasien.

\section{METODE PENELITIAN}

Penelitian ini merupakan penelitian deskriptif dengan rancangan penelitian observasional. Populasi dalam penelitian ini adalah lansia di Kelurahan Pucang Sewu, Kecamatan Gubeng, Kota Surabaya yang memenuhi kriteria inklusi yaitu lansia dengan usia 60 tahun atau lebih dan sedang mengonsumsi obat serta bersedia menjadi responden.

Pengambilan sampel pada penelitian ini menggunakan metode non-random sampling dengan teknik purposive sampling. Waktu pengambilan data dimulai dari hari Rabu, 11 September 2019 hingga Minggu, 15 September 2019 dengan mendatangi secara langsung ke beberapa rumah warga di kelurahan Pucang Sewu.

Variabel yang diteliti adalah perilaku pengelolaan obat pada lansia, meliputi cara mendapatkan, penggunaan, penyimpanan, dan pembuangan sisa atau sampah obat. Penelitian ini menggunakan data yang diperoleh dari hasil kuisioner yang diisi oleh responden. Sebelum pengambilan data, kuesioner telah dilakukan uji validitas rupa dengan cara dilakukan uji coba pada orang lain yang sesuai kriteria inklusi.

\section{HASIL DAN PEMBAHASAN}

Sebelum pengambilan data, dilakukan uji coba atau validasi rupa terhadap kuisioner yang akan digunakan. Kuisioner dinyatakan valid dengan beberapa perubahanagar dapat mewakili semua variabel pertanyaan dan mudah dimengerti oleh calon responden. Dalam penelitian ini terdapat 108 responden yang setuju untuk berpartisipasi dalam penelitian ini dari 1224 populasi lansia di kelurahan Pucang Sewu.

Sebagian besar lansia sudah mendapatkan obat dari tempat yang tepat, yaitu apotek dan puskesmas/klinik. Untuk penerimaan informasi obat, sebagian besar responden telah menerima informasi dengan jelas dari apoteker ataupun dokter. Penebusan obat atau pembelian obat untuk lansia di kelurahan Pucang Sewu sebagian besar dilakukan oleh lansia sendiri karena obat tersebut 
diperoleh di puskesmas dalam waktu yang rutin. Hal ini menjadi perhatian bahwa sebaiknya saat lansia menerima obat pihak keluarga juga turut mendampingi agar informasi yang diterima dari apoteker maupun dokter dapat tersampaikan secara sepenuhnya. Pengetahuan responden mengenai tempat perolehan obat dan penggunaan antibiotik sudah benar. Namun, pengetahuan responden mengenai adanya beberapa obat keras yang diterima tanpa resep dokter sebagian besar masih rendah. Hal ini karena responden beranggapan bahwa semua obat berlogo keras harus diperoleh dengan resep dokter (Tabel 1).

Tabel 1.Pengalaman dan Pengetahuan Responden dalam Mendapatkan Obat pada Lansia

\begin{tabular}{|c|c|c|c|c|c|}
\hline \multicolumn{6}{|l|}{ DAPATKAN } \\
\hline \multicolumn{3}{|l|}{ Pengalaman } & \multicolumn{3}{|l|}{ Pengetahuan } \\
\hline \multirow{4}{*}{$\begin{array}{l}\text { Perolehan obat untuk } \\
\text { lansia }\end{array}$} & Apotek/toko obat & $33,33 \%$ & \multirow{4}{*}{$\begin{array}{l}\text { Obat didapatkan/dibeli di } \\
\text { apotek }\end{array}$} & \multirow[t]{2}{*}{ Benar } & \multirow[t]{2}{*}{$98 \%$} \\
\hline & Puskesmas/klinik & $52,78 \%$ & & & \\
\hline & Praktek Dokter & $12,96 \%$ & & \multirow[t]{2}{*}{ Salah } & \multirow[t]{2}{*}{$2 \%$} \\
\hline & Minimarket & $0,93 \%$ & & & \\
\hline \multirow{4}{*}{$\begin{array}{l}\text { Orang } \\
\text { menebus/membeli } \\
\text { untuk lansia }\end{array}$} & Anggota Keluarga & $48,15 \%$ & \multirow{4}{*}{$\begin{array}{l}\text { Beberapa obat dengan logo } \\
\text { obat keras boleh dibeli tanpa } \\
\text { resep dokter }\end{array}$} & Benar & $27 \%$ \\
\hline & Lansia Sendiri & $51,85 \%$ & & \multirow[t]{3}{*}{ Salah } & \multirow[t]{3}{*}{$73 \%$} \\
\hline & Perawat & $0 \%$ & & & \\
\hline & Tetangga & $0 \%$ & & & \\
\hline \multirow{2}{*}{$\begin{array}{l}\text { Penerimaan informasi } \\
\text { obat untuk lansia }\end{array}$} & $\mathrm{Ya}$ & $87 \%$ & \multirow{2}{*}{$\begin{array}{l}\text { Antibiotik dapat diminum } \\
\text { sampai habis meskipun sudah } \\
\text { sembuh }\end{array}$} & Benar & $85 \%$ \\
\hline & Tidak & $13 \%$ & & Salah & $15 \%$ \\
\hline
\end{tabular}

Berdasarkan Tabel 2, pengalaman responden dalam mengguanakan obat sebagian besar sudah benar. Sebagian besar pasien lansia masih dapat meminum obat sendiri tanpa bantuan siapapun. Hasil survei tentang pengalaman responden mengenai penggunaan obat dapat diketahui bahwa hampir seluruh responden sudah memahami cara penggunaan obat serta memperhatikan tanggal kadaluwarsa obat. Pasien lansia yang memahami hal ini tidak terlepas dari pemberian informasi saat konseling mengenai obat yang dikonsumsi. Pemberian informasi mengenai cara penggunaan dan tanggal kadaluwarsa merupakan aspek yang penting untuk meningkatkan kepatuhan (BPOM RI, 2015).

Tabel 2. Pengalaman dan Pengetahuan Responden dalam Menggunakan Obat pada Lansia

\begin{tabular}{|c|c|c|c|c|c|}
\hline \multicolumn{6}{|l|}{ GUNAKAN } \\
\hline \multicolumn{3}{|l|}{ Pengalaman } & \multicolumn{3}{|l|}{ Pengetahuan } \\
\hline \multirow[t]{4}{*}{$\begin{array}{l}\text { Orang yang membantu minum } \\
\text { obat untuk lansia }\end{array}$} & $\begin{array}{l}\text { Anggota Keluarga } \\
\text { lansia }\end{array}$ & $18.52 \%$ & \multirow{6}{*}{$\begin{array}{l}\text { Efek samping dan cara } \\
\text { penggunaan obat harus } \\
\text { diperhatikan }\end{array}$} & \multirow[t]{3}{*}{ Benar } & \multirow[t]{3}{*}{$94 \%$} \\
\hline & Lansia sendiri & $81.48 \%$ & & & \\
\hline & Perawat & $0 \%$ & & & \\
\hline & Tetangga & $0 \%$ & & \multirow[t]{3}{*}{ Salah } & \multirow[t]{3}{*}{$6 \%$} \\
\hline \multirow{2}{*}{$\begin{array}{l}\text { Paham istilah-istilah yang } \\
\text { terdapat pada kemasan obat }\end{array}$} & $\mathrm{Ya}$ & $64 \%$ & & & \\
\hline & Tidak & $36 \%$ & & & \\
\hline \multirow{2}{*}{$\begin{array}{l}\text { Penggunaan obat sudah sesuai } \\
\text { aturan pakai }\end{array}$} & $\mathrm{Ya}$ & $94 \%$ & \multirow{6}{*}{$\begin{array}{lcr}\text { Aturan } & \text { minum } & \text { sirup } \\
\text { satu sendok } & \text { makan } \\
\text { sama dengan } & \text { tiga } \\
\text { sendok takar } & \end{array}$} & \multirow[t]{3}{*}{ Benar } & \multirow[t]{3}{*}{$30 \%$} \\
\hline & Tidak & $7 \%$ & & & \\
\hline \multirow{2}{*}{$\begin{array}{l}\text { Pemahaman cara penggunaan } \\
\text { obat untuk lansia yang didapat }\end{array}$} & $\mathrm{Ya}$ & $99 \%$ & & & \\
\hline & Tidak & $1 \%$ & & \multirow[t]{3}{*}{ Salah } & \multirow[t]{3}{*}{$70 \%$} \\
\hline \multirow{2}{*}{$\begin{array}{l}\text { Kepedulian keluarga dalam } \\
\text { mengingatkan atau menyiapkan } \\
\text { untuk minum obat pada lansia }\end{array}$} & $\mathrm{Ya}$ & $60 \%$ & & & \\
\hline & Tidak & $40 \%$ & & & \\
\hline \multirow{2}{*}{$\begin{array}{l}\text { Kesulitan lansia saat minum } \\
\text { obat }\end{array}$} & $\mathrm{Ya}$ & $13 \%$ & \multirow{6}{*}{$\begin{array}{l}\text { Obat digunakan sesuai } \\
\text { dengan aturan pakai } \\
\text { yang ada dikemasan }\end{array}$} & \multirow[t]{3}{*}{ Benar } & \multirow[t]{3}{*}{$70 \%$} \\
\hline & Tidak & $87 \%$ & & & \\
\hline \multirow{2}{*}{$\begin{array}{l}\text { Kepatuhan lansia meminum } \\
\text { semua obat jika mendapatkan } 5 \\
\text { atau lebih }\end{array}$} & $\mathrm{Ya}$ & $54 \%$ & & & \\
\hline & Tidak & $46 \%$ & & \multirow[t]{3}{*}{ Salah } & \multirow[t]{3}{*}{$30 \%$} \\
\hline \multirow{2}{*}{$\begin{array}{l}\text { Perhatian terhadap tanggal } \\
\text { kadaluarsa obat }\end{array}$} & $\mathrm{Ya}$ & $75 \%$ & & & \\
\hline & Tidak & $25 \%$ & & & \\
\hline
\end{tabular}


Sebagian besar anggota keluarga lansia juga mengingatkan atau menyiapkan obat untuk diminum oleh lansia. Peran keluarga dalam mengingatkan atau menyiapkan obat sangat berperan dalam meningkatkan kepatuhan pasien lansia sebagai support system. Ada hubungan yang signifikan antara peran keluarga yang selalu memotivasi dengan meningkatnya kepatuhan pasien dalam pengobatan (Rohmayani, 2018). Meskipun kebanyakan lansia di kelurahan Pucang sewu tidak memiliki kesulitan minum obat, namun pada aspek kepatuhan minum obat hanya sebagian dari lansia yang meminum seluruh obat jika mendapat obat lebih dari 5 jenis. Jumlah obat lebih dari 5 jenis, pasien maupun keluarga harus mengingat banyak waktu dalam mengonsumsi obat. Hal ini dapat menurunkan tingkat kepatuhan pasien lansia (Muharrir, et al., 2015).

Pada Tabel 3, pengalaman responden pada penyimpanan obat sangat bervariasi. Untuk tempat penyimpanan obat, sebagian besar menjawab dalam kotak obat. Namun, penyimpanan di sembarang tempat juga masih dilakukan oleh sebagian responden $(21 \%)$. Selain itu, jumlah responden yang memperhatikan dan tidak memperhatikan tanggal kadaluwarsa menunjukkan hasil yang hampir sama. Hampir $50 \%$ responden yang memperhatikan tanggal kadaluwarsa obat, sedangkan sisanya tidak memperhatikan dikarenakan kemasan obat yang diterima tidak utuh sehingga tanggal kadaluarsa obat tidak tampak. Hasil pengetahuan responden mengenai penyimpanan obat menunjukkan bahwa responden telah mengetahui penyimpanan obat yang baik $(54.6 \%)$ yaitu di dalam kemasan asli dan disimpan dikotak obat atau sesuai suhu penyimpanan yang disarankan. Responden juga sudah mengetahui bahwa udara yang lembab adalah salah satu yang dapat menyebabkan obat rusak.

Tabel 3. Pengalaman dan Pengetahuan Responden dalam Menyimpan Obat pada Lansia

\begin{tabular}{|c|c|c|c|c|c|}
\hline \multicolumn{6}{|l|}{ SIMPAN } \\
\hline \multicolumn{3}{|l|}{ Pengalaman } & \multicolumn{3}{|l|}{ Pengetahuan } \\
\hline \multirow{4}{*}{$\begin{array}{l}\text { Tempat penyimpan } \\
\text { obat }\end{array}$} & Kotak obat & $54,63 \%$ & \multirow{3}{*}{$\begin{array}{l}\text { Penyimpanan obat yang } \\
\text { dalam kemasan asli } \\
\text { diletakkan di kotak obat }\end{array}$} & Benar & \multirow{3}{*}{$\frac{91 \%}{9 \%}$} \\
\hline & Lemari & $17,59 \%$ & & Salah & \\
\hline & Kulkas & $6,48 \%$ & & & \\
\hline & Sembarang tempat & $21,30 \%$ & \multirow{3}{*}{$\begin{array}{l}\text { Udara yang } \\
\text { menyebabkan obat rusak }\end{array}$} & Benar & $84 \%$ \\
\hline \multirow{2}{*}{$\begin{array}{l}\text { Perhatian terhadap } \\
\text { tanggal kadaluwarsa }\end{array}$} & $\mathrm{Ya}$ & $49 . \%$ & & Salah & $16 \%$ \\
\hline & Tidak & $51 \%$ & & & \\
\hline
\end{tabular}

Tabel 4, menunjukkan pengalaman responden terhadap pembuangan obat dalam berbagai cara. Sebagian besar lansia menjawab bahwa obat yang didapatkan diminum sampai habis sehingga jarang menyisakan obat. Hal ini dikarenakan di kelurahan Pucang Sewu, obat diberikan sesuai rentang waktu pakai sampai obat tersebut habis selama seminggu dari pihak puskesmas lansia. Untuk pembuangan obat, sebagian besar $(60.2 \%)$ menjawab langsung membuangnya di tempat sampah tanpa dihancurkan terlebih dahulu. Pengetahuan responden mengenai pembuangan obat menunjukkan beberapa responden belum mengetahui bahwa obat tablet seharusnya dihancurkan terlebih dahulu sebelum dibuang. Sebaliknya pada obat sirup, sebagian besar responden telah mengetahui bahwa obat sirup dibuang dengan mengeluarkan isinya ke saluran air.

Tabel 4. Pengalaman dan Pengetahuan Responden dalam Membuang Obat pada Lansia

\begin{tabular}{|c|c|c|c|c|c|}
\hline \multicolumn{6}{|l|}{ BUANG } \\
\hline Pengalaman & & & Pengetahuan & & \\
\hline \multirow{4}{*}{$\begin{array}{l}\text { Perlakuan terhadap sisa } \\
\text { obat lansia yang sudah } \\
\text { tidak digunakan }\end{array}$} & Disimpan & $37,04 \%$ & \multirow{4}{*}{ 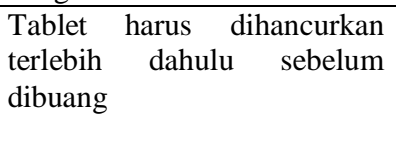 } & \multirow[t]{2}{*}{ Benar } & \multirow[t]{2}{*}{$61 \%$} \\
\hline & Dibuang & $18,52 \%$ & & & \\
\hline & Diminum sampai habis & $43,52 \%$ & & Salah & $39 \%$ \\
\hline & Diberikan ke orang lain & $0,92 \%$ & & & \\
\hline \multirow[t]{4}{*}{ Cara pembuangan obat } & $\begin{array}{l}\text { Obat dihancurkan } \\
\text { terlebih dahulu }\end{array}$ & $14,81 \%$ & \multirow{4}{*}{$\begin{array}{l}\text { Obat sirup dibuang dengan } \\
\text { cara mengeluarkan sisa obat } \\
\text { ke saluran air }\end{array}$} & \multirow[t]{2}{*}{ Benar } & \multirow[t]{2}{*}{$79 \%$} \\
\hline & Tidak membuang & $11,11 \%$ & & & \\
\hline & Dibuang ke saluran air & $13,89 \%$ & & \multirow[t]{2}{*}{ Salah } & \multirow[t]{2}{*}{$21 \%$} \\
\hline & $\begin{array}{l}\text { Dibuang ke tempat } \\
\text { sampah }\end{array}$ & $60,19 \%$ & & & \\
\hline
\end{tabular}


Berdasarkan Gambar 1 pada kolom pengalaman, persentase tertinggi terdapat pada kriteria dapatkan sedangkan persentase terendah terdapat pada kriteria buang. Pada kolom pengetahuan, persentase tertinggi terdapat pada kriteria simpan sedangkan persentase terendah terdapat pada kriteria dapatkan dan buang (Gambar 2). Sementara itu, perbandingan antara pengalaman dan pengetahuan responden mengenai DAGUSIBU pengelolaan obat pada lansia. Pada kriteria dapatkan dan gunakan, persentase pengalaman lebih tinggi daripada pengetahuan (Gambar 3). Hal ini menunjukkan bahwa lansia di Kelurahan Pucang Sewu telah menerapkan kriteria dapatkan dan gunakan obat dengan baik dan benar walaupun sedikit mengetahui informasi tentang dapatkan dan gunakan obat. Pada kriteria simpan dan buang, persentase pengetahuan lebih tinggi dibandingkan pengalaman. Hal ini berartisebenarnya lansia telah mengetahui cara menyimpan dan membuang obat dengan baik namun belum menerapkannya secara baik dan benar.

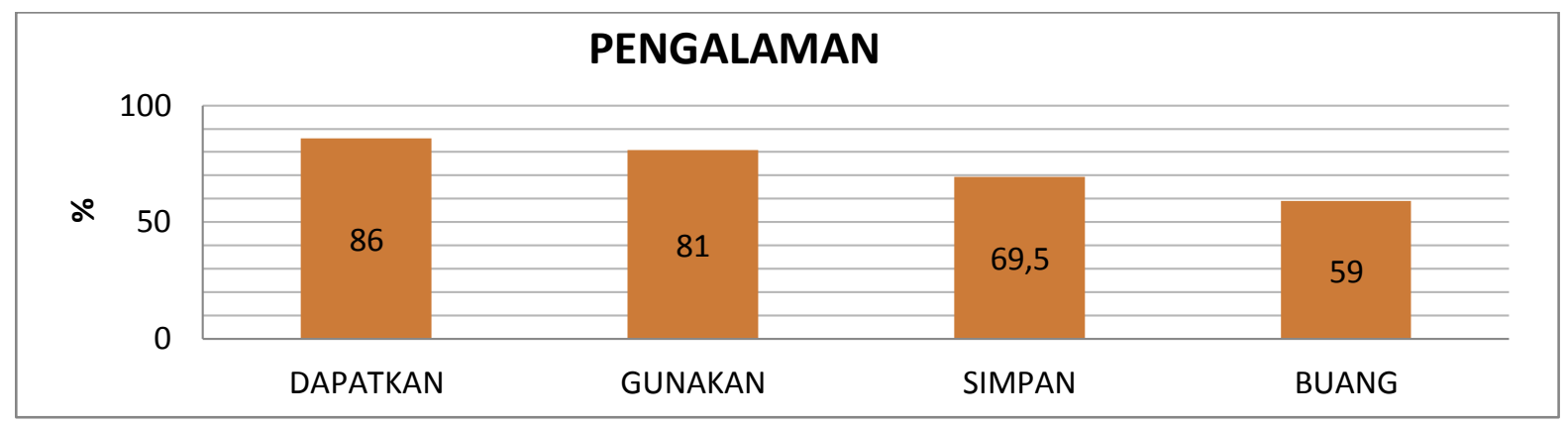

Gambar 1. Persentase Pengalaman DAGUSIBU Obat pada Lansia

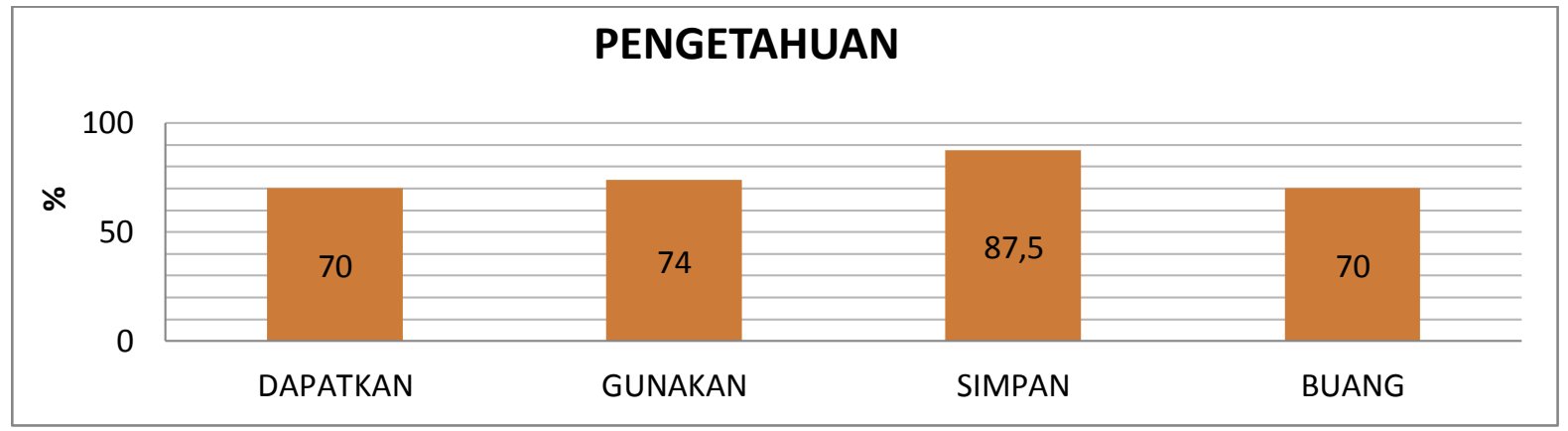

Grafik 2.Persentase Pengetahuan DAGUSIBU Obat pada Lansia

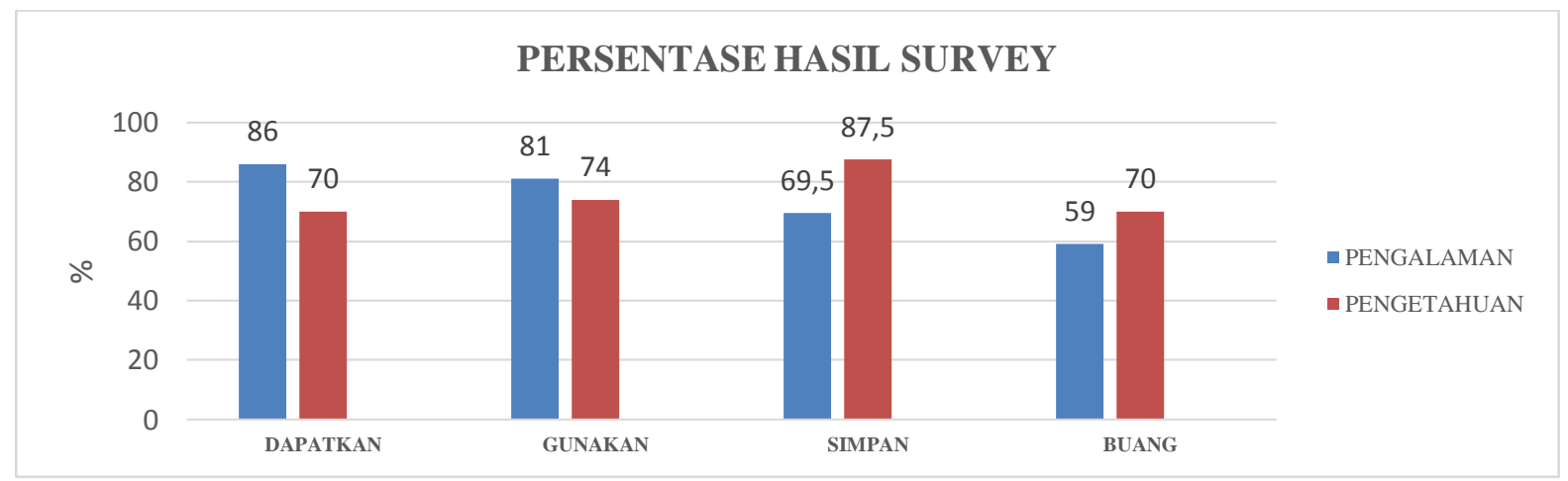

Grafik 3.Persentase antara Pengalaman dan Pengetahuan DAGUSIBU Obat pada Lansia 


\section{KESIMPULAN}

Sebagian besar populasi lansia di kelurahan Pucang Sewu telah memahami cara untuk mendapatkan dan menggunakan obat dengan baik dan benar. Namun, sebagian besar lansia masih kurang memahami cara menyimpan dan membuang obat yang baik dan benar. Saran yang dapat kami berikan kepada masyarakat luas agar lebih memperhatikan tentang pengelolaan obat terutama aspek penyimpanan dan pembuangan obat yang baik dan benar sehingga didapatkan outcome terapi yang diharapkan. Untuk apoteker dan tenaga kesehatan lain adalah agar dapat memberikan edukasi kepada pasien mengenai DAGUSIBU, sehingga masyarakat lebih mengetahui tentang cara mendapatkan, menggunakan, menyimpan, dan membuang obat dengan baik dan benar.

\section{DAFTAR PUSTAKA}

BPOM RI 2015, Pemberian Informasi untuk Meningkatkan Kepatuhan Pasien (viewed 24 Agustus http://pionas.pom.go.id/ioni/lampiran-6- petunjuk-praktis-penggunaan-obat-yangbenar/pemberian-informasi-obat-untuk.

Muharrir, M, Ridwan, M, Maulana, R 2015, 'Hubungan polifarmasi dengan tingkat kepatuhan minum obat pasien gagal jantung di Rumah Sakit Umum Daerah dr. Zainoel Abidin Banda Aceh' Skripsi, Universitas Syiah Kuala.

Rohmayani, SA 2018, 'Hubungan dukungan keluarga dengan kepatuhan pengobatan pada lansia penderita hipertensi di Dusun Pundung Cambahan Nogotirto Sleman Yogyakarta' Skripsi, Universitas 'Aisyiyah Yogyakarta.

DepKes RI 2017, Analisis Lansia Indonesia 2017 (viewed 19 September 2019), www.depkes.go.id/resources/download/pusdat in/lainlain/Analisis\%20Lansia\%20Indonesia\% 202017.pdf .

Presiden RI 2014, Pelaksanaan Upaya Peningkatan Kesejahteraan Sosial Lanjut Usia, Pemerintah Pusat Republik Indonesia, Jakarta.

MenKes RI 2014, Pelayanan Kefarmasian di Rumah (Home Pharmacy Care), Pemerintah Pusat Republik Indonesia, Jakarta. 